\title{
Numerical Simulation of Fluid-Structure Interaction for Wind-induced Dynamic Response of Low-rise Lightweight Buildings with Different Roof Pitches
}

\author{
Zhenhua Liu, a , Qianyi Wang ${ }^{1, a}$ and Limei Tian ${ }^{1, a}$ \\ ${ }^{1}$ School of Civil Engineering, Shandong University, Jinan 250061, China \\ aemmanualw@163.com
}

\begin{abstract}
Keywords: low-rise lightweight buildings, fluid-structure interaction, wind pressure distributed coefficient, wind-induced vibration coefficient

Abstract. Low-rise buildings such as lightweight portal frames are often very susceptible to wind effects, owing to their light weight and large span. The numerical simulation analysis of fluid-structure interaction of low-rise lightweight buildings with different roof pitches is performed by ADINA to investigate the wind-induced dynamic response in this paper. The effects of roof pitches on the distribution characteristics of the surface wind load on the roofs under different parameters are analyzed by numerical results, such as wind pressure distributed coefficients and wind-induced vibration coefficients, which can be used in the design of Low-rise buildings.
\end{abstract}

\section{Introduction}

Many surveys indicate that a very considerable proportion of buildings damaged by wind are low-rise lightweight buildings. Owing to their light weights and large spans, such kind of buildings are often very susceptible to wind effects.

Wind load shape coefficients can reflect the magnitude and distribution of wind pressure . The current load code $[1,2]$ has some imperfections in which the load cade does not consider the change of wind load shape coefficients of building roofs within certain roof pitches.

Recent years, many researchers have done some numerical simulations of the low-rise gable roof buildings, which are limited to rigid models. Few people considered the fluid-structure interaction. The numerical simulation analysis of fluid-structure interaction (FSI) of lightweight portal frames with different roof pitches is performed by ADINA to investigate the wind-induced dynamic response in this paper. The conclusions can provide some references for the engineering design and research of low-rise lightweight buildings.

\section{Numerical Simulation Model}

To ensure the request of stiffness and strength, we design all kinds of the sections of the portal frame on the basis of actual dimension and load. The roof panel is discretized by 4 nodes shell element, while the member bars of column and beam are discretized by 2 nodes beam element and supporting rods are discretized by truss element, which are illuminated in Figure 1.

According to structure size, the dimension of the computational fluid domain is $288 m \times 270 m \times 36 m$, the structure locates $90 \mathrm{~m}$ away from the entrance. The flow domain is discretized by 8 -node hexahedron FCBI-C [3] fluid element. The air is assumed as viscous incompressible flow and its density is $1.225 \mathrm{~kg} / \mathrm{m}^{3}$, the viscosity is $1.78 \times 10^{-5} \mathrm{~kg} / \mathrm{m} \cdot \mathrm{s}$. The turbulence model is SST model and use the transient solution method.The basic wind pressure standard value is $0.45 \mathrm{kN} / \mathrm{m}^{2}$. The direction of the wind goes along the positive $\mathrm{Y}$ axis in figures 2 . The fluid model is given in Figure 2 and 3. 

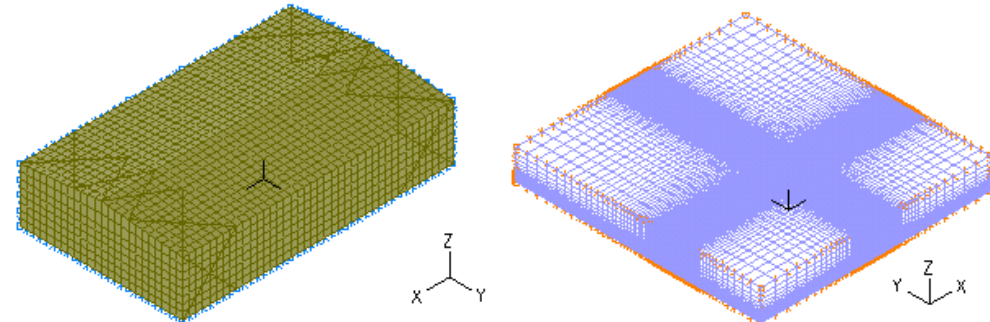

Figure 1 Finite Element Structure Model Figure 2 Mesh of fluid field

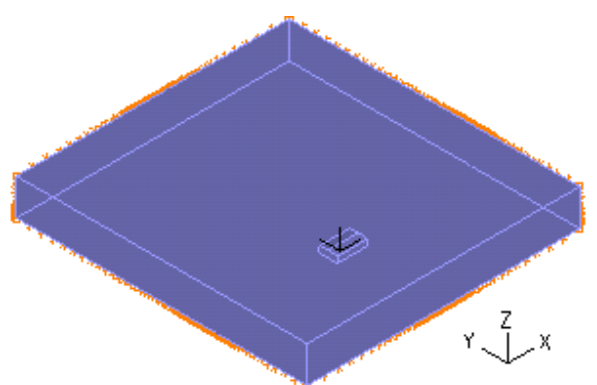

Figure 3 Scenograph

The sizes of lightweight portal frames with different roof pitches are shown in Table 1.

Table 1 Computational models with different roof pitches

\begin{tabular}{|c|c|c|c|c|c|}
\hline Model No. & Length $(\mathrm{m})$ & Width $(\mathrm{m})$ & $\begin{array}{c}\text { The height of } \\
\text { eaves }(\mathrm{m})\end{array}$ & $\begin{array}{c}\text { The height of } \\
\text { ridges }(\mathrm{m})\end{array}$ & $\begin{array}{c}\text { Roof } \\
\text { pitches }\end{array}$ \\
\hline 1 & 30 & 18 & 6 & 6.9 & $1 / 10$ \\
\hline 2 & 30 & 18 & 6 & 7.35 & $1.5 / 10$ \\
\hline 3 & 30 & 18 & 6 & 7.8 & $2 / 10$ \\
\hline 4 & 30 & 18 & 6 & 8.25 & $2.5 / 10$ \\
\hline 5 & 30 & 18 & 6 & 8.7 & $3 / 10$ \\
\hline
\end{tabular}

\section{The Numerical Simulation Results}

\section{Wind Pressure Distribution Coefficient}

The equation of wind pressure distribution coefficient is

$$
C_{p i}=2\left(P_{i}-P_{0}\right) / \rho v_{0}^{2}
$$

where $P_{i}$ is the pressure of the measured point $i$ on the surface, $P_{0}$ is the reference pressure, $v_{0}$ is the average wind speed of reference height, $\rho$ is air density. Wind pressure distribution coefficient contour lines are shown in Figure 4.

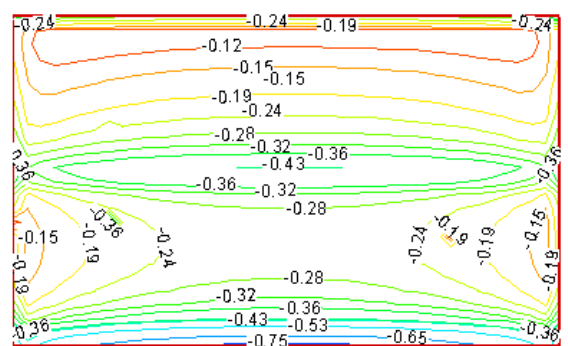

(a) roof pitch $=1 / 10$

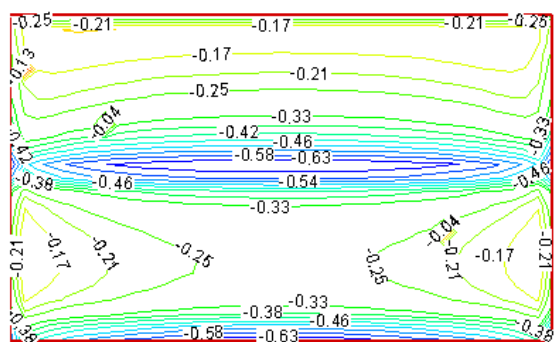

(b) roof pitch $=1.5 / 10$

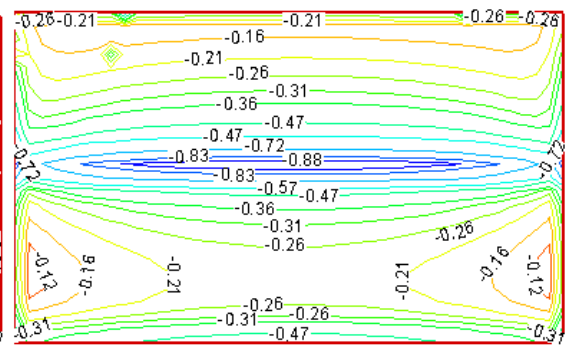

(c) roof pitch $=2 / 10$

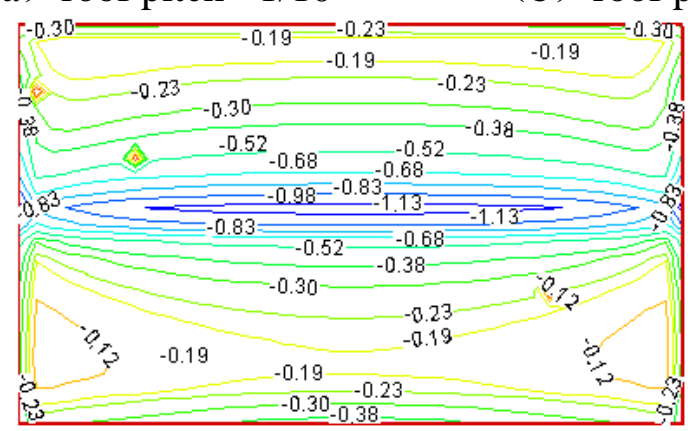

(d) roof pitch $=2.5 / 10$

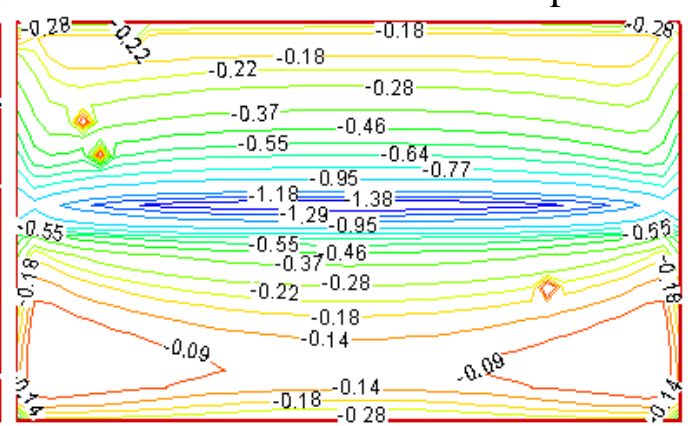

(e) roof pitch $=3 / 10$

Figure 4 Wind pressure distribution coefficient contour lines 
From Figure 4 and reference [4], we can see that when the roof pitch is $1 / 10$ or $1.5 / 10$, the largest negative pressure appears at the eave of the windward. When the roof pitch increases to $2 / 10$, it appears at the ridge. When roof pitches are less than 3/10, coefficients of the windward eave marginal zone become greater and those of the ridge become lower with the increase of the roof pitch.

\section{Wind shape coefficients and wind-induced vibration coefficients of roof subareas}

The roof subareas. According to the 《Technical specification for steel structure of light-weight buildings with gabled frames》, the roof is divided into many subareas. Area A and C are angle zones, area $\mathrm{B}$ and $\mathrm{F}$ are eave marginal zones, area D1 and D2 are gable marginal zones, area E1 and E2 are middle zones.

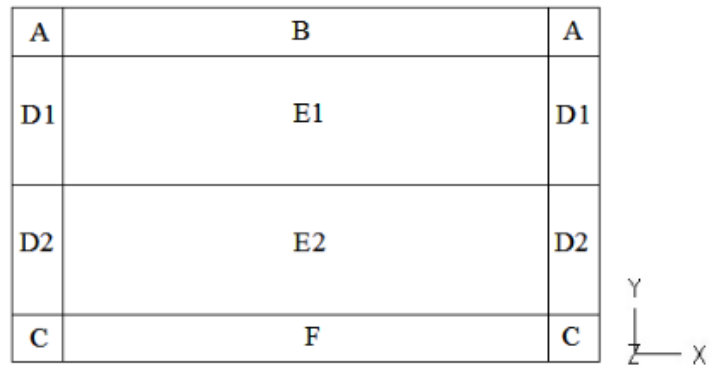

Figure 5 The roof subareas

In fact, the damage of the whole roof begins with the local damage, so it is significant to study the local wind pressure and wind-induced vibration coefficient.In the practical engineering, the average value of wind pressure coefficients is used as the wind shape coefficient, that is

$$
\mu_{s i}=\frac{\sum C_{p i} A_{i}}{A}
$$

Wind shape coefficients of roof subareas. These coefficients are given in Figure 6.
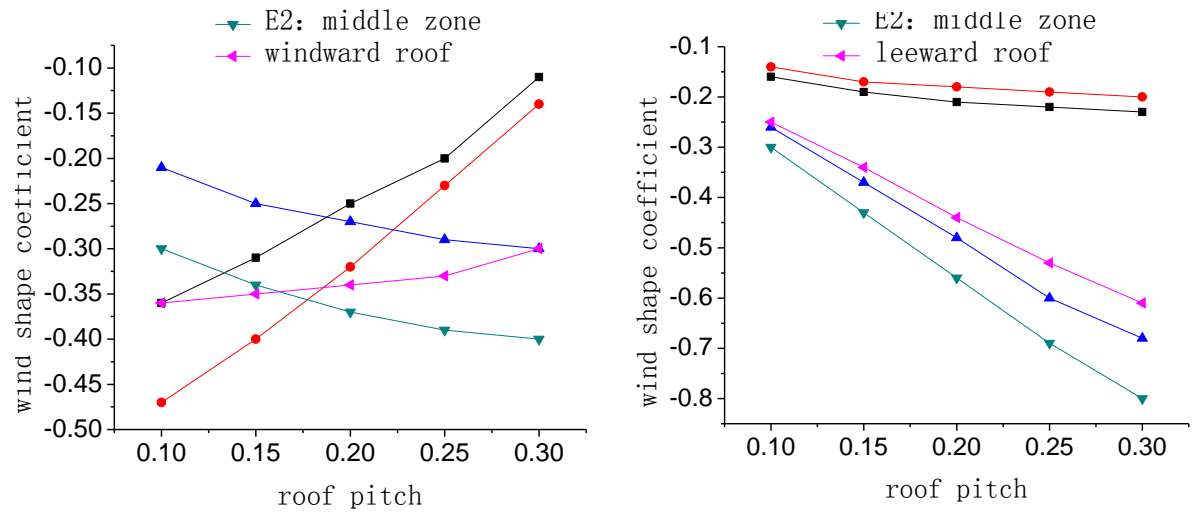

Figture 6 The wind shape coefficients of windward roofs and leeward roofs

From Figure 6, the average wind shape coefficients of a windward roof become larger with the increase of the roof pitch. When the roof pitch is small, the wind shape coefficients of the eave marginal zone are smaller than the average coefficients. When the roof pitch is large, the coefficients of the middle zone are smaller than the average coefficients, and other zones are larger than them.

With the increase of the roof pitch, the average wind shape coefficients of a leeward roof decrease. Under various roof pitches, coefficients of the angle zone and gable marginal zone are larger than the average coefficients, the other zones are the opposite. The coefficients of the middle zone are 
smallest in all roof subareas.

\section{Wind-induced vibration coefficients of roof subareas.}
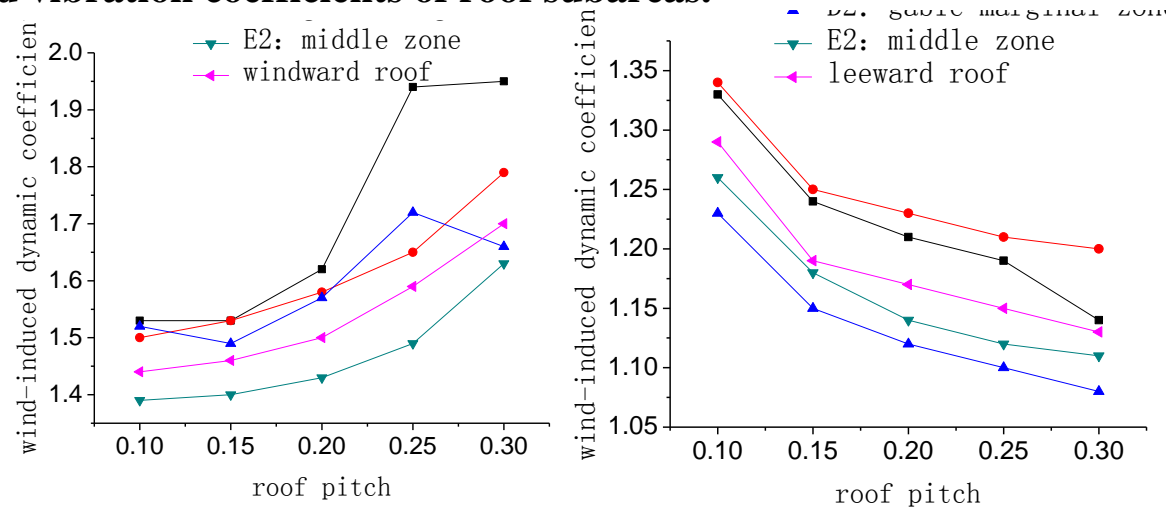

Figure 7 The wind-induced vibration coefficients of windward roofs and leeward roofs

From Figure 7, the average wind-induced vibration coefficients and all the subareas of a windward roof become larger with the increase of the roof pitch. The wind-induced vibration coefficients of the middle zone are smaller than the average coefficients, and the others are larger than them. In the subareas of a windward roof, the wind-induced vibration coefficients of the angle zone are largest.

The average wind-induced vibration coefficients and all the subareas of a leeward roof become smaller with the increase of the roof pitch. In the subareas of a leeward roof, the coefficients of the eave marginal zone are largest.

Analyze the figure 6 and 7, we can see that a windward roof is easier to be damaged than a leeward roof, more common in the marginal zone, when the roof pitch is smaller.The ridged zone and gable marginal zone are easiest to damage when the roof pitch is larger.

\section{Conclusion}

The numerical simulation of the low-rise buildings with different roof pitches is performed in this paper, and the wind pressure distribution coefficients and wind-induced vibration coefficients of the roof are detained. The main results are as follows. The wind suction of a windward roof changes little, but the wind suction of a leeward roof becomes greater with the increase of the roof pitch. When the roof pitch is small, a windward roof is easier to damage than a leeward roof, and the biggest suction appears on the eave marginal zone of a windward roof. When the roof pitch is large, a leeward roof is easier to damage than a windward roof, and the biggest suction appears on the gable marginal zone and the ridge of a leeward roof. The conclusions can provide references for the engineering design of the low-rise lightweight buildings.

\section{Reference}

[1] Load code for the design of building structures, China.GB50009-2001[S]. China building industry press, (2002).

[2] Technical specification for steel structure of light-weight buildings with gabled frames, China. CECS 102: 2002[S]. China planning press, (2002).

[3] Zhenhua Liu. Numerical Simulation of Fluid-Structure Interaction for Wind-induced Dynamic Response of Membrane Structures [D].Department of Civil Engineering of Tongji University, (2006) [4] Limei Tian. Numerical Simulation of Fluid-Structure Interaction for Wind-induced Dynamic Response of Low-rise Lightweight Buildings [D]. School of Civil Engineering of Shandong University, (2009) 